Article

\title{
Probing the Molecular Interactions of Chitosan Films in Acidic Solutions with Different Salt Ions
}

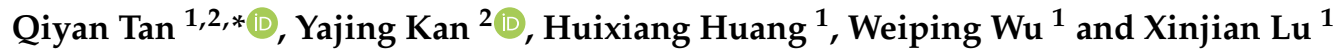 \\ 1 School of Mechanical Engineering, Nanjing Institute of Technology, Nanjing 211167, China; \\ huanghx@njit.edu.cn (H.H.); wuweiping40@njit.edu.cn (W.W.); njitlxj@njit.edu.cn (X.L.) \\ 2 School of Mechanical Engineering, Southeast University, Nanjing 211189, China; yajingkan@seu.edu.cn \\ * Correspondence: tanqiyan@njit.edu.cn
}

Received: 28 September 2020; Accepted: 28 October 2020; Published: 30 October 2020

check for updates

\begin{abstract}
Understanding the interaction mechanisms of chitosan films plays a central role in a wide range of its applications, such as bioadhesive, drug delivery, wound healing, tissue engineering, and wastewater treatment for heavy metal ions. Here, we investigated the molecular interactions between chitosan films in acidic solutions with different salt ions using a surface forces apparatus (SFA). The results showed that chitosan can be adsorbed to mica surfaces by electrostatic interaction under acidic conditions. The force measurements demonstrated that the interactions depend on the salt types, concentrations, and contact time. With the addition of $1 \mathrm{mM} \mathrm{LaCl}_{3}$ and $\mathrm{NaCl}$ into the acetic acid (HAc) buffer solution, the cohesion between chitosan films enhanced by about $45 \%$ and $20 \%$, respectively, after a contact time of $60 \mathrm{~min}$. The enhanced cohesion induced by the combination of partly intermolecular complexation formation in a bridge model and conformation adjustment of chitosan under contact time in $1 \mathrm{mM} \mathrm{LaCl}_{3}$ solution. However, the cohesion reduced rapidly and even disappeared when the salt concentration increased to $10 \mathrm{mM}$ and $100 \mathrm{mM}$. We proposed that the cross-linked structures of chitosan mainly contribute to the significant reduction of chitosan cohesion in $\mathrm{LaCl}_{3}$ solution. In comparison, the decrease in cohesion capacity in $\mathrm{NaCl}$ solution mainly results from the enhanced hydration effect. Our findings may provide insights into the interaction mechanisms of chitosan films under nanoconfinement in acidic conditions and suggestions for the development of chitosan-based materials.
\end{abstract}

Keywords: chitosan; molecular interactions; cohesion forces; salt ions; hydration effect

\section{Introduction}

Chitosan is a linear polysaccharide composed of randomly distributed $\beta-(1-4)$-linked D-glucosamine and N-acetyl-D-glucosamine units [1]. Generally, chitosan is the deacetylated derivative of chitin, an essential component of fungal cell walls, crustacean shells, and some parasites [2]. The structure and physicochemical properties of chitosan mainly depend on its molecular weight, the degree of deacetylation (DDA), the $\mathrm{pH}$ and ionic strength in solution [3]. The solubility of chitosan is strongly related to the protonation degree of amino groups. Chitosan behaves as a weak cationic polyelectrolyte in dilute acidic solutions with most amino groups being protonated. As a natural biopolymer, chitosan possesses excellent biocompatibility and admirable biodegradability with ecological safety, low toxicity with versatile biological activities, and susceptibility to enzymatic degradation [4]. Therefore, chitosan is considered to be a promising functional material in various applications such as drug delivery [5], pharmaceutical industry [6], food science [7], implants [8], bioadhesives $[9,10]$, and biomaterial [11]. Chitosan is particularly advantageous because it contains plenty of reactive sites other than amino groups, such as hydroxyl and acetyl groups. These reactive sites are easily modified and functionalized, and can interact with other molecules (e.g., polymer, 
peptide drugs), nanoparticles, living tissues, and substrates by means of electrostatic interaction, van der Waals attraction, hydrogen bonds, and hydrophobic interaction. A comprehensive exploration of the interaction behaviors and mechanisms of chitosan is crucial to the rational design and application of chitosan-based biomaterials.

Several influencing factors (e.g., $\mathrm{pH}$, contact time, molecular weight, concentration, and type of salt) which mainly governs the degree of chitosan interactions, have been confirmed by both experiments [12-15] and simulations [16]. The interactions between native chitosan films in aqueous solutions appear $\mathrm{pH}$-dependent [13]. At acidic $\mathrm{pH}$ conditions, positively charged chitosan in solutions can adhere more strongly with the negatively charged surface (e.g., mica [17-19], silica [20]) via electrostatic forces, hydrogen bonds, and van der Waals forces. The structures of bonded chitosan vary with their DDA, molecular weight, and solution conditions [21]. Previous work [13] observed slight cohesion between chitosan films due to the formation of polymer bridges. This observation is inconsistent with the theoretical expectations. Because chitosan contains both hydrophobic methyl groups and hydrogen bond sites, they can contribute to the formation of strong hydrophobic and hydrogen bond interactions. Through adhesion and cohesion measurements between adsorbed chitosan films by surface forces apparatus (SFA), Lee et al. [14] found that contact time plays a critical role in the cohesion between chitosan films. The cohesion can be enhanced by the increase in contact time, when chitosan can adjust to suitable conformations to form hydrophobic interactions and hydrogen bonds. Additionally, the cohesion of chitosan is dependent on its molecular weight. Low molecular weight chitosan chains become very stiff rod-like cationic chains in acidic solutions [15]. It is more difficult to establish a hydrogen bonds network between two opposing surfaces than that in high molecular weight chitosan. Thus, the cohesion between chitosan was reduced. Moreover, the adhesive properties and interactions of chitosan can be tuned by chemical modification and cross-linking on possible sites, such as $-\mathrm{OH},-\mathrm{NH}_{3}{ }^{+},-\mathrm{CH}_{2} \mathrm{OH},-\mathrm{NHCOCH}_{3}$, and $\mathrm{NH}_{2}$ groups. Chitosan is capable of forming thermally stable gels very rapidly in the presence of an acidic cross-linking agent [22-24], such as carboxylic acid, polyphosphates, or other multivalent ions. The cross-linked chitosan films show higher effective modulus and adhesion hysteresis during adhesion measurements [12]. Among these interactions mentioned above, hydrogen bonds are most important for the bonding strength, which can further be improved with the blending of an additive. Functional modification of chitosan with polyethylene glycol (PEG) by amino group substitution can improve its cohesion, solubility, and flexibility. The improvement of cohesion is most likely due to the increasing amount of hydrogen bonds between the chitosan backbones and the PEG side chains as well as the entanglement of the PEG side-chains [25]. These results provide important information regarding the chitosan adhesion and interactions at interfaces as well as contribute to the general knowledge in the field of chitosan-derived materials.

Moreover, the coexistence between cations and chitosan is inevitable in most chitosan applications [26]. Chitosan may complex with specific metal cations. The metal cation-chitosan complexation has been applied in wastewater treatment for heavy metal and potable water purification [27-29]. The formation and stability of the complexation also depend on the DDA of chitosan [30], the molecular weight [31], the $\mathrm{pH}$ [17], the temperature [32], and the speciation of metal ions [33-36]. The mechanisms responsible for complex formation between chitosan and metal ions include various processes such as adsorption [37], ion exchange [38], and chelation [39]. Although many works have been dedicated to the formation of metal-chitosan complexation, only a few of them aim at gaining a better understanding of the binding mechanism of metal cations to chitosan. Generally, the binding mechanism is primarily attributed to electrostatic attraction or ion exchange for chitosan interacting with a metal anion or coordinative complexation for the case with a metal cation [6]. The interpretation of binding mechanisms mainly classified the bridge model and pendant model. The same metal cation is bound with several amino groups from the same chain or different chains in the bridge model [31], while the metal cation is bound to the amino group as a pendant in the pendant model [40]. 
However, the molecular mechanisms of the interactions between chitosan films under aqueous conditions with different salt ions are scarce. A detailed molecular-level understanding of the complex interplay between chitosan and salt ions as well as its influences on surface interactions is essential for applications of chitosan and chitosan-based materials. SFA has been extensively used in studying the governing forces of many biological and non-biological systems [41], due to its unique ability to measure simultaneously the interaction force and the local geometry of two interacting surfaces in situ and in real-time. Coupling with our previous work [42], here we investigated the interaction and cohesion forces between two chitosan films using an SFA in acidic conditions $(\mathrm{pH}=3.2)$ with salt-free, 1,10 , and $100 \mathrm{mM} \mathrm{LaCl}_{3}$ and $\mathrm{NaCl}$. The results showed obvious cohesion enhancement firstly with the addition of $1 \mathrm{mM}$ salt ions in acidic solutions, whereas the strength of cohesion reduced gradually and finally disappeared when the salt concentrations increased to 10 and $100 \mathrm{mM}$. This work provides a better insight into the applications of chitosan biopolymer both in biomedical applications and the development of chitosan-based materials.

\section{Materials and Methods}

Chemicals. All chemicals were used without further purification. Highest grade (Grade 1) muscovite mica was purchased from S\&J Trading Inc. (New York City, NY, USA). Chitosan (product number 448869) with a molecular weight about 50-190 kDa was purchased from Sigma-Aldrich (Shanghai, China), the structure is illustrated in Figure 1. The DDA of chitosan was more than $75.0 \%$. The glassware was washed in advance with sulfuric acid to remove any organic contaminant. Chitosan solution $(10 \mu \mathrm{g} / \mathrm{mL})$ was prepared by dissolving chitosan solute in $100 \mathrm{mM}$ acetic acid (HAc) buffer (Sigma-Aldrich). The solution was then gently stirred overnight at room temperature. $\mathrm{NaCl}$ and $\mathrm{LaCl}_{3}(99.9 \%$, Sigma-Aldrich) were dissolved in $100 \mathrm{mM}$ HAc buffer to obtain buffer solutions with different salt concentrations, including 1, 10, and $100 \mathrm{mM}$. The $\mathrm{pH}$ values of all solutions were titrated to 3.2 after solution preparations to exclude the negative influence of high $\mathrm{pH}$ on chitosan interactions. Ultrapure water was obtained from a water purification system, with the resistivity of $18.2 \mathrm{M} \Omega \cdot \mathrm{cm}$. All the solutions were filtered using the syringe filters with $0.22-\mu \mathrm{m}$ pore size (Whatman, Guangzhou, China) before use.

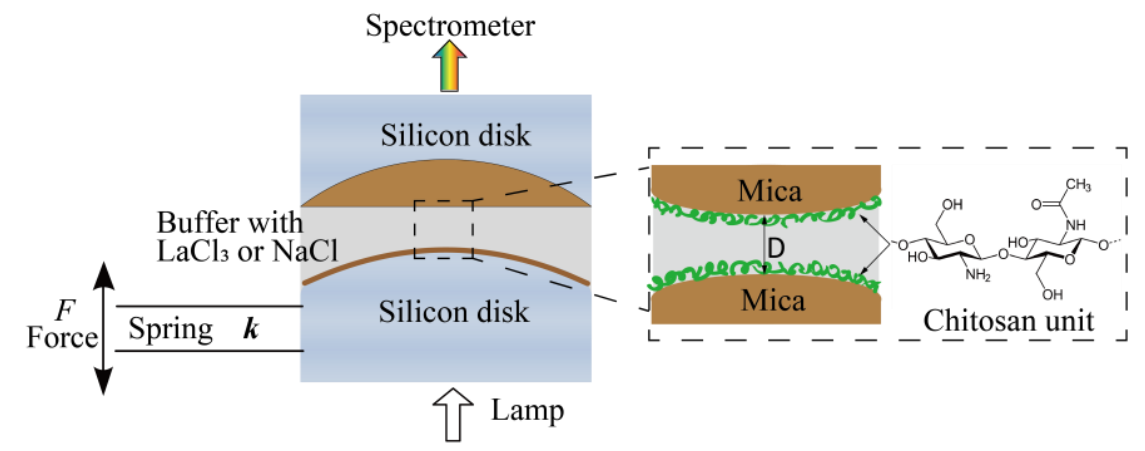

Figure 1. Schematic of the experimental setup and chemical structures of chitosan.

Sample preparation. Atomically smooth mica sheets with a thickness from 2 to $5 \mu \mathrm{m}$ were coated with a 55-nm-thick silver layer. Two back-silvered mica surfaces were then glued on cylindrical silica disks using EPON1004F (Shell Chemicals, Shanghai, China). Chitosan was incubated by dipping glued mica surfaces into $10 \mu \mathrm{g} / \mathrm{mL}$ chitosan HAc buffer solution for $20 \mathrm{~min}$. Then, the surfaces were washed extensively with $100 \mathrm{mM}$ HAc buffer to remove those free or loosely adsorbed chitosan molecules. A droplet of HAc was left on each surface at the end of surface preparation. The whole procedure was performed in a laminar flow hood.

Interaction forces measurements. Interactions between two chitosan-coated mica surfaces across different aqueous buffer solutions were directly measured by an SFA-2000 system from SURFORCE, LLC at Santa Barbara (CA, USA), which has been previously described [43-45]. The schematic of the 
experimental setup in this work was shown in Figure 1. A pair of chitosan-coated mica surfaces were transferred into the SFA chamber in a crossed-cylinder geometry, which corresponds to a sphere of radius $R$ approaching a flat surface. Based on the Derjaguin approximation, the interaction energy per unit area between two flat surfaces $(E(D))$ can be obtained by $E(D)=F(D) / 2 \pi R$, where $F(D)$ is the force between the two curved surfaces, $R$ is the radius of the cylindrical silica disk (usually $\sim 2 \mathrm{~cm}$ ), and $D$ is the surface separation distance between two bare mica surfaces. The lower surface was connected to a motor, which allows the two surfaces to move relative to each other at a controlled speed $(\sim 2 \mathrm{~nm} / \mathrm{s}$ in this study). During the experiments, a droplet of $100 \mathrm{mM} \mathrm{HAc}$ buffer $(\mathrm{pH}=3.2)$ was injected into the gap of surfaces when the chitosan-coated mica surfaces were mounted into the SFA chamber. The chamber was sealed and the whole system remained until equilibrium was reached, at which point the force profiles were measured. The two chitosan-coated mica surfaces were approached to contact firstly, external compression remained on them for at least $2 \mathrm{~min}$ to reach a closer contact, followed by leaving the surfaces unperturbed for a contact time of 1, 5, 30, and $60 \mathrm{~min}$. Finally, the surfaces were driven apart to investigate the effect of contact time on cohesion forces of the chitosan films. Interaction (cohesion) energy $E_{\text {ad }}$ between two surfaces can be determined from the pull-off force $\left(F_{\text {pull }}\right)$ taken at the jump-out position by $E_{\mathrm{ad}}=2 F_{\text {pull }} / 3 \pi R$, which is described by the Johnson-Kendall-Roberts (JKR) model for soft materials with large deformations. The force measurements were also performed in 1 , 10 , and $100 \mathrm{mM} \mathrm{LaCl}_{3}$ or $\mathrm{NaCl}(\mathrm{pH}=3.2$ ) buffer solutions, respectively, to study the influence of salts and concentration on surface interactions. In these measurements, $F(D)$ profiles were measured three times at each condition to confirm the reproducibility. A calibration procedure was performed before each experiment to determine the distance of zero $(D=0)$ between two bare mica surfaces. The forces $F(D) / R$ were measured with an accuracy of about $10 \mathrm{nN} / \mathrm{m}$ and distances with an accuracy of $\pm 0.1 \mathrm{~nm}$. All the measurements were conducted at room temperature of $22^{\circ} \mathrm{C}$.

\section{Results and Discussion}

\subsection{Interactions between Chitosan Films in HAc Buffer Solutions}

Before the tests with the effect of salt ions, the interactions between two chitosan-coated mica surfaces in salt-free HAc buffer solutions were obtained firstly as control references. The surface interactions between chitosan-coated mica surfaces in $100 \mathrm{mM}$ salt-free HAc buffer, at $\mathrm{pH} 3.2$, was shown in Figure 2a. The force profiles exhibit a long-range and exponentially decay electrostatic double-layer repulsion, which was observed at $\sim 30 \mathrm{~nm}$ separation. Steric repulsion emerges at a separation of $D_{\mathrm{s}} \approx 3.6 \pm 0.4 \mathrm{~nm}$, indicating the beginning of the interpenetration of adsorbed chitosan molecules. At $\mathrm{pH} 3.2$, the electrostatic repulsion between protonated amino groups prevents the chitosan chains from aggregating, the chitosan exhibits a flattened structure intimately adsorbed on a mica surface. When the initially adsorbed chitosan was slightly pressed, the hardwall thickness $\left(D_{\mathrm{h}}\right)$, which represents the thickness of the chitosan films confined between two micas surfaces, reduced to $\sim 2.5 \pm 0.3 \mathrm{~nm}$ as the load reaching $\sim 10 \mathrm{mN} / \mathrm{m}$. Here, the $D_{\mathrm{h}}$ of $\sim 2.5 \pm 0.3 \mathrm{~nm}$ indicated that a chitosan film of thickness 1.1-1.4 nm was deposited on each mica substrate in pure HAc solutions. The thickness of adsorbed chitosan films is consistent with other reports [14] and thicker than that on the silica surface [20]. The $D_{\mathrm{h}}$ reduced to $1.6 \pm 0.2 \mathrm{~nm}$ at a higher load (about $30 \mathrm{mN} / \mathrm{m}$ ), corresponding to a $0.7-0.9 \mathrm{~nm}$ adsorbed film on each mica surface. It is difficult to obtain detailed configurations of chitosan under nanoconfinement in our experiments, but the $D_{\mathrm{h}}$ indicated a flat configuration of chitosan film on mica. By taking HAc buffer as a 1:1 electrolyte solution with about $0.6 \%$ of acetic acid molecules being dissociated [46], the Debye length of the double-layer structure at mica surface can be calculated. We also fitted the forces-distance profiles with the DLVO theory (Derjaguin-Landau-Verwey-Overbeek), which summed the electrostatic double-layer forces and van der Waals forces in the additive [44]. The fitting parameters are the Debye length and surface potential for a general estimation. The solid line in Figure 2a represents the prediction of the DLVO model. The calculation results showed a negligible deviation from the measured decay lengths. 

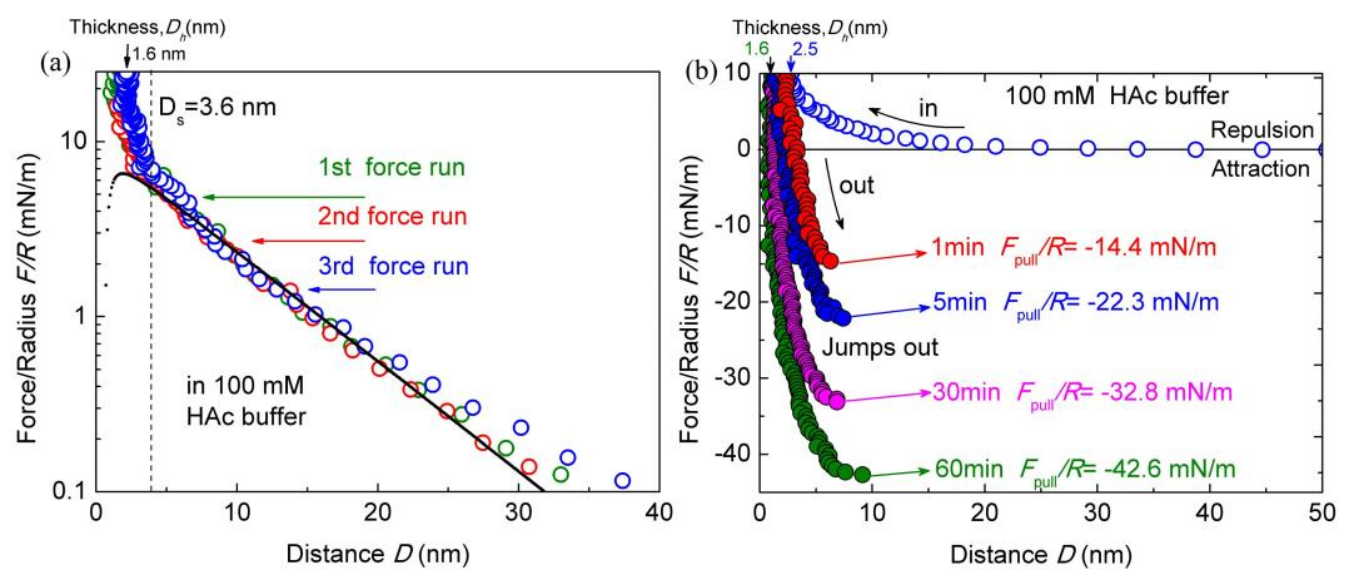

Figure 2. Interaction forces $F / R$ as a function of surface separation $D$ between two chitosan-coated mica surfaces in $100 \mathrm{mM}$ acetic acid (HAc) buffer, $\mathrm{pH}=3.2$. (a) Semi-log plot of $F / R$ versus $D$; (b) the open and closed symbols indicate the approach and separation of the two mica surfaces, respectively.

To assess the contact time effect on the interactions of chitosan films, the pull-off forces $F_{\text {pull }}$ between two surfaces during the separation process were measured with different contact times. Two chitosan-coated mica surfaces were firstly brought into contact until the load reached up to $\sim 10 \mathrm{mN} / \mathrm{m}$, followed by leaving the contacted surfaces unperturbed for different contact times of $1,5,30$, and $60 \mathrm{~min}$. Then, the surfaces were separated. During the separation process, the lower surface jumps away from the upper surface at certain distances, which was contributed by the cohesion between the two surfaces. The force profiles are presented in Figure $2 \mathrm{~b}$. It can be found that the cohesion forces between chitosan films depend strongly on the contact time. The measured cohesion increases by about three times when increasing the contact time from 1 to $60 \mathrm{~min}$. During separation, a strong pull-off force of $F_{\text {pull }} / R \approx-14.4 \pm 0.9 \mathrm{mN} / \mathrm{m}$ was measured between chitosan films with the contact time of $1 \mathrm{~min}$, corresponding to cohesion energy of $E_{\mathrm{ad}} \approx-3.0 \pm$ $0.2 \mathrm{~mJ} / \mathrm{m}^{2}$. By extending the contact time to 5,30 , and $60 \mathrm{~min}$, the pull-off force $F_{\text {pull }} / R$ values were enhanced to $-22.3 \pm 1.1 \mathrm{mN} / \mathrm{m}\left(E_{\mathrm{ad}} \approx-4.7 \pm 0.2 \mathrm{~mJ} / \mathrm{m}^{2}\right),-32.8 \pm 1.3 \mathrm{mN} / \mathrm{m}\left(E_{\mathrm{ad}} \approx-7.0 \pm 0.3 \mathrm{~mJ} / \mathrm{m}^{2}\right)$, and $-42.6 \pm 1.8 \mathrm{mN} / \mathrm{m}\left(E_{\mathrm{ad}} \approx-9.1 \pm 0.4 \mathrm{~mJ} / \mathrm{m}^{2}\right)$, respectively. The measured pull-off forces and cohesions are consistent with the previous report [14] except for the contact time of $1 \mathrm{~min}$. This discrepancy may be induced by the higher load (about $10 \mathrm{mN} / \mathrm{m}$ ) in this experiment than that (about $4 \mathrm{mN} / \mathrm{m}$ ) in the report. With the increase in contact time, the steric hardwall decreases from $\sim 2.5 \pm 0.3$ to $\sim 1.6 \pm 0.2 \mathrm{~nm}$ gradually. That is, the chitosan films adjust their conformation under the prolonged contact time. Increasing contact time also changed the jump-out distance, where the separation between two mica surfaces happened. The jump-out distance points increased from $6.5 \pm 0.2$ (1 $\mathrm{min})$ to $9.1 \pm 0.5 \mathrm{~nm}(60 \mathrm{~min})$, which is likely due to the enhanced interdigitations and strengthened cohesions with prolonged contact time.

It is well known that chitosan contains both hydrophobic methyl groups and hydrogen bond sites, which can contribute to the formation of hydrophobic interaction and hydrogen bonds, respectively [25]. According to previous work [14], chitosan molecules appear as both a relaxed twofold helix and extended twofold helix in acidic solutions. Generally, the relaxed twofold helix structure does not easily form hydrophobic interaction and hydrogen bonds, whereas the extended twofold helix structure could promote the formation of these interactions. The conformation of chitosan molecules may be adjusted as the local surroundings around the chitosan molecules change. As proposed in previous work [14], the contact time effect on chitosan cohesion could be explained by the fact that the chitosan molecule may rearrange itself from a relaxed twofold helix to an extended structure. Additionally, the conformation arrangement of chitosan chains can also be monitored from the decrease in $D_{\mathrm{h}}$ with the increase in contact time. After certain contact time, the $D_{\mathrm{h}}$ was found to decrease from $2.5 \pm 0.3$ to $1.6 \pm 0.2 \mathrm{~nm}$ for $60 \mathrm{~min}$. These observations are typical characters of the arrangements of chitosan 
conformation and formation of a physical interaction bond. The self-adapted conformations can easily form hydrogen bonds and hydrophobic interaction between chitosan-coated surfaces, resulting in stronger cohesion interactions. Furthermore, the decrease in electrostatic and steric repulsion during confinement between chitosan-coated surfaces can increase the cohesion force slightly. Therefore, the conformation change and rearrangement of chitosan molecules are the main reason for the cohesion enhancement between chitosan-coated surfaces with the increase in contact time.

\subsection{Interactions between Chitosan Films in HAc Buffer Solutions with Salt Ions}

\subsubsection{Effects of Salt Ions Types}

The conformation and interaction of chitosan may be changed with different types of salt ions. To examine the effect of salt ions on chitosan films, the interactions of chitosan-coated mica surfaces were measured in HAc buffer solutions with different salt ions. Figure 3a shows the typical force-distance profiles between chitosan-coated mica surfaces in HAc buffer solutions with $1 \mathrm{mM} \mathrm{LaCl} 3$ during approach and separation. The other experimental conditions herein are the same as the salt-free case.
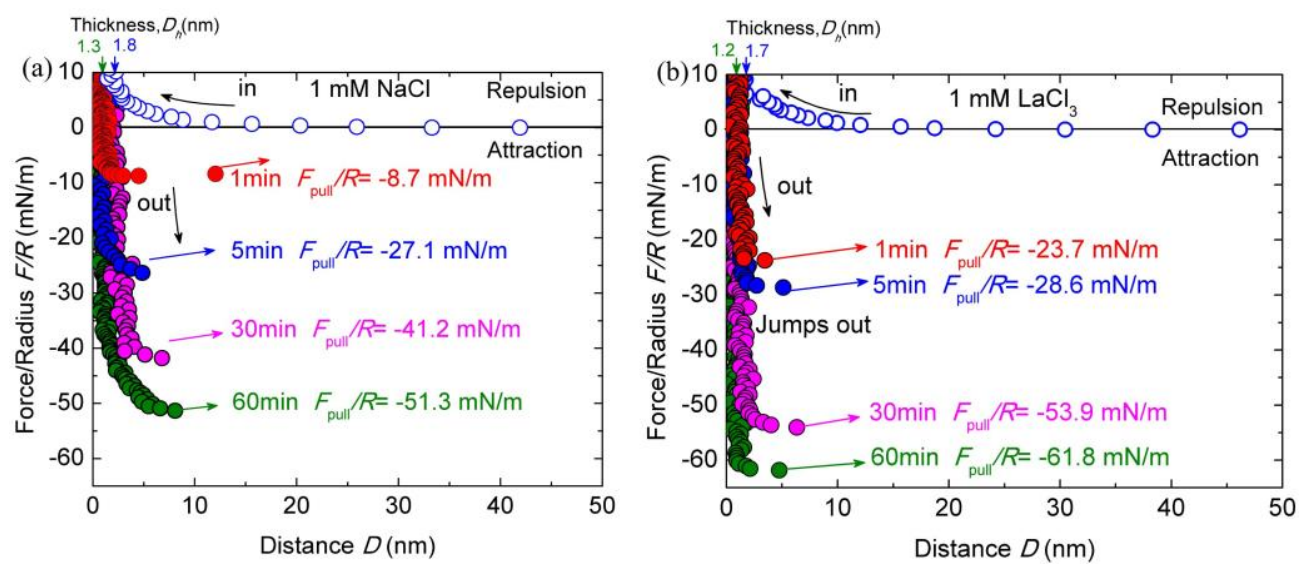

Figure 3. Interaction forces $F / R$ as a function of surface separation $D$ between two chitosan-adsorbed mica surfaces in $100 \mathrm{mM}$ HAc buffer with $1 \mathrm{mM} \mathrm{LaCl}_{3}(\mathbf{a})$ and $\mathrm{NaCl}(\mathbf{b}), \mathrm{pH}=3.2$. The open and closed symbols indicate the approach and separation of the two surfaces, respectively.

As shown in Figure 3a, both the surface forces and the $D_{\mathrm{h}}$ vary significantly with the addition of salt ions. Once $1 \mathrm{mM} \mathrm{LaCl}{ }_{3}$ was introduced through buffer exchange, the $D_{\mathrm{h}}$ reduced from $\sim 2.5 \pm 0.3$ to $\sim 1.7 \pm 0.2 \mathrm{~nm}$ at the steric repulsion of $\sim 10 \mathrm{mN} / \mathrm{m}$ during the surfaces approach, indicating that the adsorbed chitosan layer on each mica got thinner by $0.4 \mathrm{~nm}$. The thickness of $D_{\mathrm{h}}$ stabilized at $\sim 1.2 \pm 0.2 \mathrm{~nm}$ after the contact time of $60 \mathrm{~min}$, corresponding to about $\sim 0.6 \pm 0.1 \mathrm{~nm}$ thickness of chitosan films on each mica surface. Therefore, the conformation of chitosan films became flattened on mica surfaces with the addition of $1 \mathrm{mM} \mathrm{LaCl}_{3}$. The repulsion force was initiated at $\sim 17 \mathrm{~nm}$, which is shorter than that in pure HAc buffer solution. As the addition of $1 \mathrm{mM} \mathrm{LaCl}{ }_{3}$ increased the ionic strength in buffer solutions, the decay length was expected to be shortened and electrostatic repulsion was weakened. The cohesion forces were greatly enlarged with the addition of $1 \mathrm{mM} \mathrm{LaCl} 3$ at a given contact time compared to those in salt-free HAc buffer. The puff-off force increased from $-14.4 \pm 0.9 \mathrm{mN} / \mathrm{m}\left(E_{\mathrm{ad}} \approx-3.05 \pm 0.2 \mathrm{~mJ} / \mathrm{m}^{2}\right)$ in pure HAc buffer to $-23.7 \pm 0.8 \mathrm{mN} / \mathrm{m}\left(E_{\mathrm{ad}} \approx-5.8 \pm 0.2 \mathrm{~mJ} / \mathrm{m}^{2}\right)$ in $1 \mathrm{mM} \mathrm{LaCl} 3 \mathrm{HAc}_{3}$ buffer with only 1-minute contact. By prolonging the contact time to 5,30 and $60 \mathrm{~min}$, the maximum puff-off forces were enhanced to $-28.6 \pm 1.0 \mathrm{mN} / \mathrm{m}\left(E_{\mathrm{ad}} \approx-7.7 \pm 0.2 \mathrm{~mJ} / \mathrm{m}^{2}\right),-53.9 \pm 1.4 \mathrm{mN} / \mathrm{m}\left(E_{\mathrm{ad}} \approx-11.4 \pm 0.3 \mathrm{~mJ} / \mathrm{m}^{2}\right)$ and $-61.8 \pm 1.8 \mathrm{mN} / \mathrm{m}\left(E_{\mathrm{ad}} \approx-13.1 \pm 0.3 \mathrm{~mJ} / \mathrm{m}^{2}\right)$, respectively. With respect to the film thickness, the $D_{\mathrm{h}}$ under different contact times were measured to slightly fluctuate within the error.

Given that the cohesion between chitosan films was significantly enhanced with the addition of $1 \mathrm{mM} \mathrm{LaCl} 3$ in the HAc buffer, it seemed appropriate to examine the effect of type of salt 
ions on chitosan film interactions. To further clarify the effects of salt ions on the cohesion of chitosan, the force-distance profile between two chitosan-coated mica surfaces was investigated by using the acetic solutions containing $1 \mathrm{mM} \mathrm{NaCl}$, as shown in Figure $3 \mathrm{~b}$. In $1 \mathrm{mM} \mathrm{NaCl}$ solution, the repulsion between chitosan films is observed at $\sim 19 \mathrm{~nm}$ on the approach process. The force range is shorter than that in $100 \mathrm{mM}$ salt-free HAc buffer. With the increase in the contact time, the $D_{\mathrm{h}}$ decreased from $\sim 1.8 \pm 0.2$ to $1.3 \pm 0.1 \mathrm{~nm}$, which corresponds to an adsorbed chitosan film with a thickness of $\sim 0.6 \pm 0.1 \mathrm{~nm}$ on each mica surface. Slight cohesion capacity decrease was observed after introducing $1 \mathrm{mM} \mathrm{NaCl}$ between chitosan films with 1-min contact time, but prolonged contact time $(60 \mathrm{~min})$ resulted in a significant enhancement cohesion, which reached $F_{\text {pull }} / R \approx-51.3 \pm 1.6 \mathrm{mN} / \mathrm{m}$ $\left(E_{\mathrm{ad}} \approx \sim 10.8 \pm 0.5 \mathrm{~mJ} / \mathrm{m}^{2}\right)$. Compared with the addition of $1 \mathrm{mM} \mathrm{LaCl} 3$, the magnitude of cohesion enhancement is smaller.

To make a comparison, a summary of puff-off forces is shown in Figure 4. The cohesion between chitosan films can be enhanced with the addition of $1 \mathrm{mM} \mathrm{LaCl}_{3}$ and $1 \mathrm{mM} \mathrm{NaCl}$, especially the case with long contact time. Generally, the binding of chitosan molecules to the mica surfaces relies on the protonated amino groups under acidic conditions. With the addition of salt ions, the competition effect of $\mathrm{H}^{+}$makes these binding sites inaccessible for the metal cations in acidic solution. However, as reported in previous work [45], the cation with a high valence can overcompensate the opposite surface charges under some circumstances. The strong ion-ion correlation effect of multivalent ions can result in charge reversion of the mica surface under acidic conditions. It is expectable that the $\mathrm{La}^{3+}$ cations have a higher affinity with an electronegative nitrogen atom to partly replace the proton in the protonated amino group $[47,48]$. This exchange process was analogous to ion exchange but at a slow rate due to the electrostatic barriers [42]. The exchanged chitosan molecules can be even more tightly bound with the mica substrate. Thus, the conformation of adsorbed chitosan on the mica surface becomes flatter in $1 \mathrm{mM} \mathrm{LaCl}_{3}$ solution than that in pure HAc buffer. The intermolecular hydrogen bonds and hydrophobic interactions can be formed easily under flat conformations. Moreover, $\mathrm{Cl}^{-}$anions may also adsorb on the positively charged chitosan molecules as counterions under acidic conditions. Scanning electron microscopy-energy dispersive X-ray spectrometry (SEM-EDX) analysis [49] revealed that the salt cations and anions were simultaneously adsorbed on the chitosan surface from aqueous solution. In this experiment, the existence of $\mathrm{Cl}^{-}$anions in chitosan solution has considerable potential to partly screen the positive charges of chitosan. As a consequence, the net charge of some amino groups is partly neutralized. Under a prolonged contact time, the multivalent salt ions can partly bind with several functional groups from the opposing sides' chitosan chains by intermolecular complexation in a bridge model [31]. Previous works [50,51] reported that the small amount of multivalent ion can enhance the adhesion between catechol protein surfaces by ion bridging. In our case, we speculated that the intermolecular complexation bridge combining with the hydrogen bond and hydrophobic interaction enhanced the cohesion of chitosan films in acidic solutions with the presence of $1 \mathrm{mM} \mathrm{LaCl}_{3}$. For the case of $1 \mathrm{mM} \mathrm{NaCl}$, the affinity of $\mathrm{Na}^{+}$ion is lower than $\mathrm{La}^{3+}$ ion, it is difficult to partly replace the proton in the protonated amino group. However, the ionic strength of the solution was enhanced by the introduction of a small amount of salt ions, which was companied with the compression of electrostatic barrier between the chitosan films from opposing sides. This can promote the adhesive contact as well as conformation adjustment of chitosan molecules chains under prolonged contact time. Therefore, the slight increase in cohesion between chitosan film with the addition of $1 \mathrm{mM} \mathrm{NaCl}$ is likely to be related to the electrostatic screening effect in the chitosan network. 


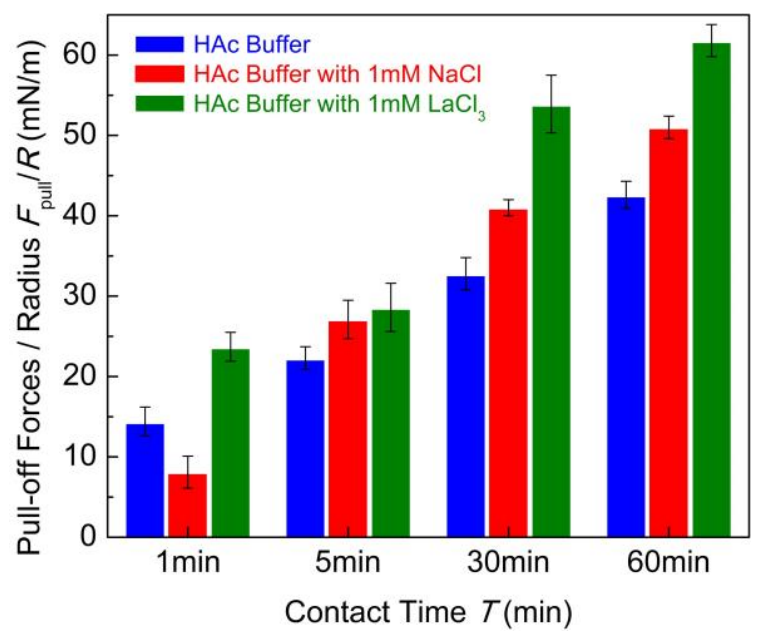

Figure 4. Pull-off forces $F_{\text {pull }} / R$ between two chitosan films in $100 \mathrm{mM}$ HAc buffer in the presence of salt-free, $1 \mathrm{mM} \mathrm{LaCl}_{3}$ and $1 \mathrm{mM} \mathrm{NaCl}$ with different contact times.

\subsubsection{Effect of Salt Ions Concentrations}

Chitosan can form gels of a complex structure under certain conditions by cross-link agent or multivalent cations, similar to other polysaccharides such as in alginate gels [52]. The binding capacities of chitosan to salt ions were influenced by many factors, such as the DDA, concentration, $\mathrm{pH}$, and salt ions concentrations and types. In order to investigate the effect of concentrations of salt ions on the molecular interactions between chitosan films, the concentrations of $\mathrm{LaCl}_{3}$ and $\mathrm{NaCl}$ in $100 \mathrm{mM} \mathrm{HAc}$ buffer solutions were increased to 10 and $100 \mathrm{mM}$, respectively.

As shown in Figure 5a,b, when the concentration of $\mathrm{LaCl}_{3}$ increased from 1 to 10 and $100 \mathrm{mM}$, the interactions between the chitosan films were obviously different. The decay length of repulsion decreased below $10 \mathrm{~nm}$ with the addition of $10 \mathrm{mM} \mathrm{LaCl}_{3}$. The $D_{\mathrm{h}}$ increased to $\sim 3.0 \pm 0.3 \mathrm{~nm}$. By extending the contact time to $60 \mathrm{~min}$, the $D_{\mathrm{h}}$ decreased to $\sim 1.4 \pm 0.2 \mathrm{~nm}$, which is thicker than those measured in salt-free and $1 \mathrm{mM}$ salt ions buffer solutions. The cohesion was totally eliminated after the contact time of $1 \mathrm{~min}$. Keeping the surfaces at contact for a longer time, the puff-off forces achieve the valves of $-8.2 \pm 0.8 \mathrm{mN} / \mathrm{m}\left(E_{\mathrm{ad}} \approx-1.7 \pm 0.2 \mathrm{~mJ} / \mathrm{m}^{2}\right)$ for $10 \mathrm{~min}$ contact, $-22.6 \pm 1.1 \mathrm{mN} / \mathrm{m}$ $\left(E_{\mathrm{ad}} \approx-4.7 \pm 0.2 \mathrm{~mJ} / \mathrm{m}^{2}\right)$ for $30 \mathrm{~min}$ contact, and $-23.7 \pm 1.0 \mathrm{mN} / \mathrm{m}\left(E_{\mathrm{ad}} \approx-4.8 \pm 0.2 \mathrm{~mJ} / \mathrm{m}^{2}\right)$ for $60 \mathrm{~min}$ contact. The cohesion capacity of the chitosan film was reduced about $55 \%$ in acidic solution compared with that measured in $1 \mathrm{mM} \mathrm{LaCl}_{3}$ for the contact time of $60 \mathrm{~min}$. 

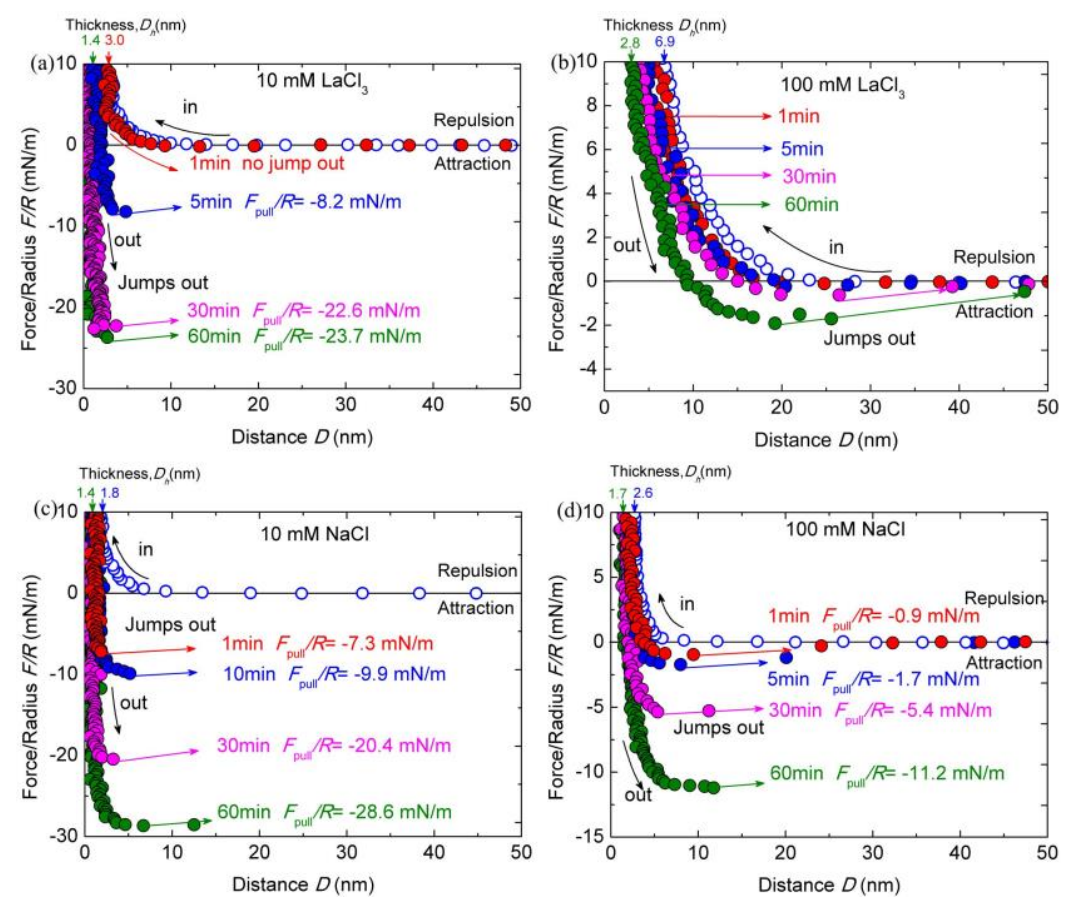

Figure 5. Interaction forces $F / R$ as a function of surface separation $D$ between two chitosan-adsorbed mica surfaces in $100 \mathrm{mM}$ HAc buffer with $10 \mathrm{mM} \mathrm{LaCl}_{3}$ (a), $100 \mathrm{mM} \mathrm{LaCl}_{3}$ (b), $10 \mathrm{mM} \mathrm{NaCl}$ (c), and $100 \mathrm{mM} \mathrm{NaCl}(\mathbf{d}), \mathrm{pH}=3.2$. The open and closed symbols indicate the approach and separation of the two surfaces, respectively.

Moreover, as the concentration of $\mathrm{LaCl}_{3}$ was further elevated to $100 \mathrm{mM}$, the cohesion nearly disappeared. The puff-off force can only reach to $-1.9 \pm 0.3 \mathrm{mN} / \mathrm{m}\left(E_{\mathrm{ad}} \approx-0.4 \pm 0.1 \mathrm{~mJ} / \mathrm{m}^{2}\right)$ even for $60 \mathrm{~min}$ contact. With respect to the film thickness, the $D_{\mathrm{h}}$ increased to $\sim 6.9 \pm 0.5 \mathrm{~nm}$, which is larger than that $(\sim 1.7 \pm 0.2 \mathrm{~nm})$ in $1 \mathrm{mM} \mathrm{LaCl}_{3}$ solution. The $D_{\mathrm{h}}$ fluctuates with the contact time, decreasing to $\sim 2.8 \pm 0.4 \mathrm{~nm}$ for $60 \mathrm{~min}$ contact. A similar cohesion reduction tendency was observed in $100 \mathrm{mM}$ HAc buffer solutions with the addition of 10 and $100 \mathrm{mM} \mathrm{NaCl}$, except the changing magnitudes, as shown in Figure $5 \mathrm{c}$,d. The repulsion force interaction range becomes much shorter due to the increase in ionic strength. The $D_{\mathrm{h}}$ increased to $\sim 1.8 \pm 0.4 \mathrm{~nm}$ and $\sim 2.6 \pm 0.4 \mathrm{~nm}$ in HAc buffer with the addition of 10 and $100 \mathrm{mM} \mathrm{NaCl}$, respectively; with the prolonged contact time, the $D_{\mathrm{h}}$ reduced to $\sim 1.4 \pm 0.2 \mathrm{~nm}$ and $\sim 1.7 \pm 0.3 \mathrm{~nm}$, respectively. At the small separation, the confined chitosan films become more compressed and the repulsive forces are dominated by steric repulsion alone. During separation, we observe obviously decreased cohesion forces with increasing $\mathrm{NaCl}$ concentration at a given contact time. The puff-off forces between chitosan films in acidic solutions with the presence of 10 and $100 \mathrm{mM} \mathrm{NaCl}$ were $-7.3 \pm 0.4\left(E_{\mathrm{ad}} \approx-1.7 \pm 0.1 \mathrm{~mJ} / \mathrm{m}^{2}\right)$ and $-0.9 \pm 0.2 \mathrm{mN} / \mathrm{m}\left(E_{\mathrm{ad}} \approx-0.2 \pm 0.1 \mathrm{~mJ} / \mathrm{m}^{2}\right)$, respectively, for 1-min contact. The cohesion can achieve to $-6.1 \pm 0.2$ and $-2.4 \pm 0.1 \mathrm{~mJ} / \mathrm{m}^{2}$ for $60 \mathrm{~min}$ contact, respectively. The cohesion force in $100 \mathrm{mM} \mathrm{NaCl}$ buffer solution almost disappears for the contact time at $1 \mathrm{~min}$.

According to the results from this control experiment, it would take an apparent variance in cohesion between chitosan surfaces with the addition of 10 and $100 \mathrm{mM}$ salts in $100 \mathrm{mM}$ HAc buffer solution. As pointed out above, the enhanced cohesion between chitosan films in $100 \mathrm{mM}$ HAc buffer with the addition of $1 \mathrm{mM} \mathrm{LaCl}{ }_{3}$ was induced by the bridge intermolecular complexation. The formation of multivalent protein-ion complexes can mediate unusual, reversible and strong interactions by regulating the ion concentrations [50,53]. With the addition of high concentration multivalent ions, the multivalent ions can cross-link the chitosan molecules with a concentration of about $10 \mathrm{mM}$ multivalent counterions [12,36]. Polyelectrolytes can even transform from extended brushes to collapsed brushes with saturated trivalent counterions [54]. In this case, more and more $\mathrm{La}^{3+}$ 
ions bind to the amino group through ion exchange and are eventually saturated with the increasing concentrations of $\mathrm{LaCl}_{3}$. The thicker $D_{\mathrm{h}}$ by strong compression in $\mathrm{HAc}$ buffer with $100 \mathrm{mM} \mathrm{LaCl} \mathrm{m}_{3}$ may be viewed as a sign of the cross-linked chitosan molecules. For cross-linked chitosan films, the surface interactions revealed longer range and more repulsive forces, due probably to the network formation resulting in a higher effective modulus of the layers [12]. The obvious force hysteresis existed between chitosan films in $\mathrm{HAc}$ buffer with $100 \mathrm{mM} \mathrm{LaCl}_{3}$ during the compression and decompression process at different contact times, which was absent in pure HAc buffer. Thus, we proposed that the chitosan films can be partly or even totally cross-linked in the highly concentrated salts. The formation of such cross-linked chitosan results in the extraordinary cohesion decrease in the chitosan and the increase in the film's thickness. Meanwhile, the ionic strength of solution was also increased with numbers of extra $\mathrm{LaCl}_{3}$ salt, making the chitosan films become more accessible for the adsorption of electrolyte ions. Note that $\mathrm{La}^{3+}$ ion is highly hydrated. More and more hydrated ions with strong hydration shells as well as hydrated $\mathrm{Cl}^{-}$ions may lead to a barrier for the cohesion of chitosan films. The hydration effect on the chitosan films is expected to become stronger with the increase in salt concentrations, which can contribute to the almost vanished cohesion in $100 \mathrm{Mm} \mathrm{LaCl}_{3}$. However, the underlying mechanism of cohesion loss may be different for the case of the addition of 10 and $100 \mathrm{mM} \mathrm{NaCl}$. The monovalent $\mathrm{Na}^{+}$ ions are more difficult to induce significant cross-linking. The steric hardwall shifts out by about $0.3 \mathrm{~nm}$ upon increasing the $\mathrm{NaCl}$ concentrations from 10 to $100 \mathrm{mM}$, implying the permeation of hydrated ions (mainly $\mathrm{Cl}^{-}$) into the confined chitosan films at a higher salt concentration. The hydrated ions can also bring the disruption of the hydrogen bonds and hydrophobic interactions, which induced the cohesion capacity loss of chitosan films with increasing $\mathrm{NaCl}$ concentration at a given contact time. Comparing with the same concentration of $\mathrm{LaCl}_{3}$ salt ions, the ionic strength of $\mathrm{NaCl}$ solution is lower, and either $\mathrm{Na}^{+}$or $\mathrm{Cl}^{-}$possesses weaker hydration energy than $\mathrm{La}^{3+}$ ions. Thus, it is reasonable that the magnitude of cohesion decrease is larger for $\mathrm{LaCl}_{3}$ salt than that for same concentration of $\mathrm{NaCl}$ salt. By extending the contact time at a given load (about $10 \mathrm{mN} / \mathrm{m}$ ), the water molecules can be squeezed out from the confined hydrated ions. The decrease in hardwall thickness was an obvious mark. Thus, the cohesion capacity can rescue to some extent by prolonging contact time.

\subsubsection{Effect of Contact Time}

Figure 6 shows the contact time evolution of the pull-off forces which reveals important implications for the underlying mechanism of chitosan film interactions. It demonstrates a correlation of cohesion increasing with contact time for each buffer condition. The introduction of salt ions can tune the cohesion between chitosan-adsorbed mica surfaces.
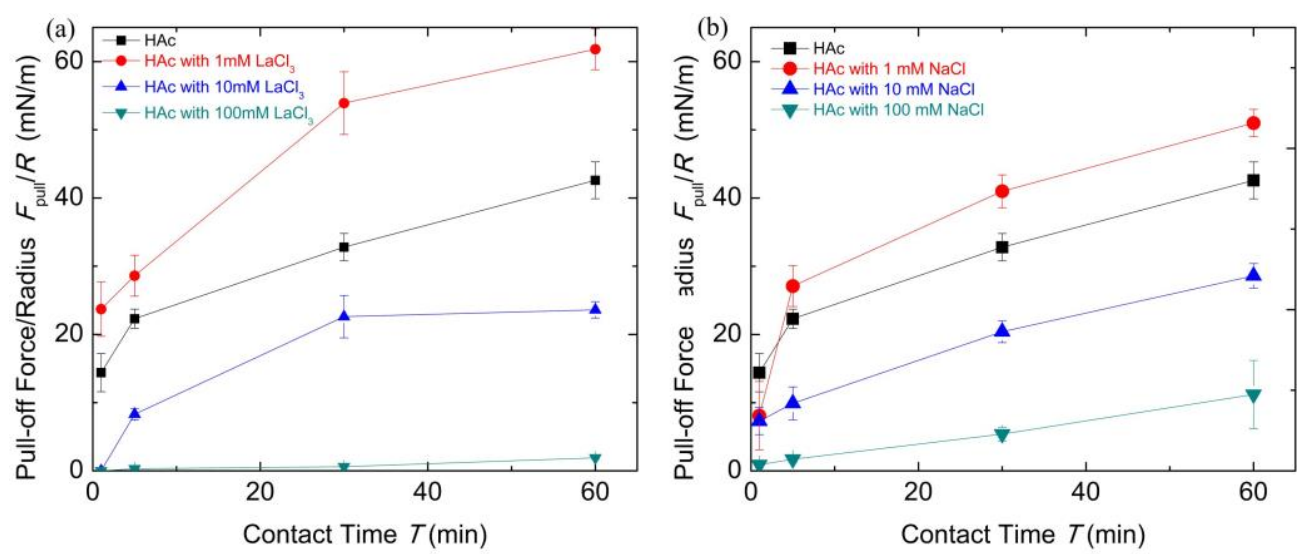

Figure 6. The pull-off forces $F_{\text {pull }} / R$ with contact time $T$ under different salt solution conditions for chitosan films obtained from surface forces apparatus (SFA) measurements. (a) The HAc buffer with different concentrations of $\mathrm{LaCl}_{3}$; (b) The HAc buffer with different concentrations of $\mathrm{NaCl}$. 
According to the results reported previously $[13,14]$, the increase in contact time allowed structural rearrangements of chitosan molecules and the enhancement of cohesion, due to the formation of hydrogen bonds and hydrophobic interactions of methyl groups by structure changes. Similar time-dependent cohesion behavior was observed in another polysaccharide biopolymer [55]. Here, from the film thinning with cohesion increasing as discussed above, we could draw a picture of the contacted chitosan films that undergo a diffusion process at prolonged contact time. When the adsorbed chitosan molecules were exposed to $1 \mathrm{mM} \mathrm{LaCl}_{3} \mathrm{HAc}$ buffer solutions, there were conformation changes in the chitosan films, and a longer relaxation time was required for the formation of effective binding. The prolonged contact time can not only adjust the conformation of chitosan molecules but may also induce the formation of intermolecular complexation in a bridge model, which can enhance the cohesion. When chitosan molecules were exposed to $100 \mathrm{mM} \mathrm{LaCl}_{3}$ solutions, the chitosan molecules can form cross-linked structures containing many hydrated salt ions. Under this condition, the contact time effect is negligible on its cohesion interactions. Nevertheless, the decrease in the chitosan film thickness with the passing of contact time indicates the adsorbed chitosan films are soft and compressible. The hydrated salt ions absorbed inside the polymer chains can be squeezed out. However, for the case of the high concentration of $\mathrm{NaCl}$ buffer solutions, the prolonged contact time mainly squeezes out the hydrated salt ions between the chitosan films that can disturb the formation of the hydrogen bonds and hydrophobic interaction. The results discussing above clearly showed the cohesion capacity recovery by means of extending the contact time. Substantially, the cohesion loss can be considered as the hydrated salt ions combined with the decrease in the number of binding groups. Therefore, this dependence of cohesion between chitosan films on contact time reminds us that chitosan, with enough relaxation time or external compression, can partly rescue its adhesive capacity which has been disrupted by salt ions.

\section{Conclusions}

The surface and cohesion forces between chitosan films adsorbed on mica surfaces in HAc buffer with different salt ions were measured using an SFA. The effects of salt concentration and cation valence were also investigated. It is found that chitosan can adsorb on the mica surface with a stable and relatively smooth configuration in HAc buffer at $\mathrm{pH} \sim 3.2$. Extending contact time can promote the molecular conformation changes of chitosan and formation of cohesion bonds (such as hydrogen bonds, hydrophobic interactions), therefore the cohesions were enhanced. The surface cohesion of chitosan films was varied by the introduction of different concentrations and types of salts. The introduction of $1 \mathrm{mM} \mathrm{LaCl}_{3}$ salts can enhance the cohesion of chitosan films by the combination of partly intermolecular complexation formation in a bridge model and conformation adjustment of chitosan under contact time. However, the introduction of 10 and $100 \mathrm{mM} \mathrm{LaCl}_{3}$ salt ions confined in chitosan can reduce cohesion interactions by cross-linked chitosan and strong hydration effects. In comparison, the loss of cohesion capacity between chitosan films in 10 and $100 \mathrm{mM} \mathrm{NaCl}$ salt solution is mainly induced by the hydration effect. The enhanced hydration effect of highly concentrated salt ions may impede the formation of effective binding between the chitosan from opposing films. Moreover, the bonds mediated by salt ions are not always stable. By applying mechanical compression on the chitosan film, part of the cohesion loss can be rescued after the release of hydrated ion and metal-ion bonds. These investigations provide insights into the interaction mechanism of chitosan molecules under acid conditions with salt ions and similar polyelectrolytes under nanoconfinement and their potential applications.

Author Contributions: Conceptualization, Q.T.; methodology, Q.T.; validation, Q.T. and Y.K.; formal analysis, Q.T. and Y.K.; investigation, Q.T., Y.K., and H.H.; resources, Q.T. and Y.K.; data curation, Q.T. and Y.K.; writing-original draft preparation, Q.T.; writing - review and editing, Q.T., Y.K., W.W., and X.L.; supervision, Q.T.; project administration, Q.T.; funding acquisition, Q.T., Y.K., H.H., and W.W. All authors have read and agreed to the published version of the manuscript. 
Funding: This research was funded by the National Natural Science Foundation of China (51605090), the Natural Science Foundation of Jiangsu Province (BK20160776), the Natural Science Foundation of the Higher Education Institutions of Jiangsu Province (18KJB460014, 18KJB410001), and the Research Foundation of Nanjing Institute of Technology (YKJ201502).

Conflicts of Interest: The authors declare no conflict of interest.

\section{References}

1. Kumar, M.N.R. A review of chitin and chitosan applications. React. Funct. Polym. 2000, 46, 1-27. [CrossRef]

2. Franca, E.F.; Freitas, L.C.G.; Lins, R.D. Chitosan molecular structure as a function of N-acetylation. Biopolymers 2011, 95, 448-460. [CrossRef] [PubMed]

3. Dash, M.; Chiellini, F.; Ottenbrite, R. Chitosan-A versatile semi-synthetic polymer in biomedical applications. Prog. Polym. Sci. 2011, 36, 981-1014. [CrossRef]

4. Shariatinia, Z. Pharmaceutical applications of chitosan. Adv. Colloid Interface Sci. 2019, 263, 131-194. [CrossRef]

5. Bhattarai, N.; Gunn, J.; Zhang, M. Chitosan-based hydrogels for controlled, localized drug delivery. Adv. Drug Deliv. Rev. 2010, 62, 83-99. [CrossRef]

6. Kumar, M.N.V.R.; Muzzarelli, R.A.A.; Muzzarelli, C.; Sashiwa, H.; Domb, A.J. Chitosan chemistry and pharmaceutical perspectives. Chem. Rev. 2004, 104, 6017-6084. [CrossRef]

7. Rinaudo, M. Chitin and chitosan: Properties and applications. Prog. Polym. Sci. 2006, 31, 603-632. [CrossRef]

8. Yi, H.; Wu, L.Q.; Bentley, W.E.; Ghodssi, R.; Rubloff, G.W.; Culver, J.N.; Payne, G.F. Biofabrication with chitosan. Biomacromolecules 2005, 6, 2881-2894. [CrossRef]

9. Patel, A.K. Chitosan: Emergence as potent candidate for green adhesive market. Biochem. Eng. J. 2015, 102, 74-81. [CrossRef]

10. Yuk, H.; Varela, C.E.; Nabzdyk, C.S.; Mao, X.; Padera, R.F.; Roche, E.T.; Zhao, X. Dry double-sided tape for adhesion of wet tissues and devices. Nat. Cell Biol. 2019, 575, 169-174. [CrossRef]

11. Williams, D.F. On the mechanisms of biocompatibility. Biomaterials 2008, 29, 2941-2953. [CrossRef] [PubMed]

12. Kampf, N.; Raviv, U.; Klein, J. Normal and shear forces between adsorbed and gelled layers of chitosan, a naturally occurring cationic polyelectrolyte. Macromolecules 2004, 37, 1134-1142. [CrossRef]

13. Claesson, P.M.; Ninham, B.W. pH-dependent interactions between adsorbed chitosan layers. Langmuir 1992, 8, 1406-1412. [CrossRef]

14. Lee, D.W.; Lim, C.; Israelachvili, J.N.; Hwang, D.S. Strong adhesion and cohesion of chitosan in aqueous solutions. Langmuir 2013, 29, 14222-14229. [CrossRef] [PubMed]

15. Lim, C.; Lee, D.W.; Israelachvili, J.N.; Jho, Y.; Hwang, D.S. Contact time- and pH-dependent adhesion and cohesion of low molecular weight chitosan coated surfaces. Carbohydr. Polym. 2015, 117, 887-894. [CrossRef] [PubMed]

16. Morrow, B.H.; Payne, G.F.; Shen, J.K. pH-responsive self-assembly of polysaccharide through a rugged energy landscape. J. Am. Chem. Soc. 2015, 137, 13024-13030. [CrossRef]

17. Khokhlova, M.A.; Gallyamov, M.O.; Khokhlov, A.R. Chitosan nanostructures deposited from solutions in carbonic acid on a model substrate as resolved by AFM. Colloid Polym. Sci. 2012, 290, 1471-1480. [CrossRef]

18. Kocun, M.; Grandbois, M.; Cuccia, L.A. Single molecule atomic force microscopy and force spectroscopy of chitosan. Colloids Surf. B Biointerfaces 2011, 82, 470-476. [CrossRef]

19. Kampf, N.; Ben-Yaakov, D.; Andelman, D.; Safran, S.A.; Klein, J. Direct measurement of sub-debye-length attraction between oppositely charged surfaces. Phys. Rev. Lett. 2009, 103, 118304. [CrossRef]

20. Tiraferri, A.; Maroni, P.; Rodríguez, D.C.; Borkovec, M. Mechanism of chitosan adsorption on silica from aqueous solutions. Langmuir 2014, 30, 4980-4988. [CrossRef]

21. Pigaleva, M.A.; Portnov, I.V.; Rudov, A.A.; Blagodatskikh, I.; Grigoriev, T.E.; Gallyamov, M.O.; Potemkin, I.I. Stabilization of chitosan aggregates at the nanoscale in solutions in carbonic acid. Macromolecules 2014, 47, 5749-5758. [CrossRef]

22. Silva, J.M.; Garcia, J.R.; Reis, R.L.; Garcia, A.J.; Mano, J.F. Tuning cell adhesive properties via layer-by-layer assembly of chitosan CrossMark and alginate. Acta Biomater. 2017, 51, 279-293. [CrossRef] [PubMed] 
23. Liu, C.; Moghaddam, S.Z.; Tyrode, E.; Claesson, P.M. Charge regulation and energy dissipation while compressing and sliding a cross-linked chitosan hydrogel layer. J. Colloid Interface Sci. 2015, 443, 162-169. [CrossRef] [PubMed]

24. Liu, C.; Thormann, E.; Claesson, P.M.; Tyrode, E. Surface grafted chitosan gels. Part I. Molecular insight into the formation of chitosan and poly (acrylic acid) multilayers. Langmuir 2014, 30, 8866-8877. [CrossRef] [PubMed]

25. Xiang, L.; Gong, L.; Zhang, J.; Zhang, L.; Hu, W.; Wang, W.; Lu, Q.; Zeng, H. Probing molecular interactions of PEGylated chitosan in aqueous solutions using a surface force apparatus. Phys. Chem. Chem. Phys. 2019, 21, 20571-20581. [CrossRef]

26. Terada, E.; Samoshina, Y.; Nylander, T.; Lindman, B. Adsorption of cationic cellulose derivatives/anionic surfactant complexes onto solid surfaces. I. Silica surfaces. Langmuir 2004, 20, 1753-1762. [CrossRef]

27. Zhang, L.; Zeng, Y.; Cheng, Z. Removal of heavy metal ions using chitosan and modified chitosan: A review. J. Mol. Liq. 2016, 214, 175-191. [CrossRef]

28. Varma, A.; Deshpande, S.; Kennedy, J. Metal complexation by chitosan and its derivatives: A review. Carbohydr. Polym. 2004, 55, 77-93. [CrossRef]

29. Guibal, E. Interactions of metal ions with chitosan-based sorbents: A review. Sep. Purif. Technol. 2004, 38, 43-74. [CrossRef]

30. Guibal, E.; Dambies, L.; Milot, C.; Roussy, J. Influence of polymer structural parameters and experimental conditions on metal anion sorption by chitosan. Polym. Int. 1999, 48, 671-680. [CrossRef]

31. Rhazi, M.; Desbrieres, J.; Tolaimate, A.; Rinaudo, M.; Vottero, P.; Alagui, A. Contribution to the study of the complexation of copper by chitosan and oligomers. Polymer 2002, 43, 1267-1276. [CrossRef]

32. Giraldo, J.D.; Rivas, B.L.; Elgueta, E.; Mancisidor, A. Metal ion sorption by chitosan-tripolyphosphate beads. J. Appl. Polym. Sci. 2017, 134, 45511. [CrossRef]

33. Kumar, N.A.; Seidel, C. Polyelectrolyte brushes with added salt. Macromolecules 2005, 38, 9341-9350. [CrossRef]

34. Lertworasirikul, A.; Tsue, S.-I.; Noguchi, K.; Okuyama, K.; Ogawa, K. Two different molecular conformations found in chitosan type II salts. Carbohydr. Res. 2003, 338, 1229-1233. [CrossRef]

35. Kawahara, M.; Yui, T.; Oka, K.; Zugenmaier, P.; Suzuki, S.; Kitamura, S.; Okuyama, K.; Ogawa, K. Fourth 3D structure of the chitosan molecule: Conformation of chitosan in its salts with medical organic acids having a phenyl group. Biosci. Biotechnol. Biochem. 2003, 67, 1545-1550. [CrossRef] [PubMed]

36. Vold, I.M.; Vårum, K.M.; Guibal, E.; Smidsrød, O. Binding of ions to chitosan-Selectivity studies. Carbohydr. Polym. 2003, 54, 471-477. [CrossRef]

37. Lasko, C.L.; Hurst, M.P. An investigation into the use of chitosan for the removal of soluble silver from industrial wastewater. Environ. Sci. Technol. 1999, 33, 3622-3626. [CrossRef]

38. Guibal, E.; Milot, C.; Roussy, J. Influence of hydrolysis mechanisms on molybdate sorption isotherms using chitosan. Sep. Sci. Technol. 2000, 35, 1021-1038. [CrossRef]

39. Inoue, K.; Baba, Y.; Yoshizuka, K. Adsorption of metal ions on chitosan and crosslinked copper(II)-complexed chitosan. Bull. Chem. Soc. Jpn. 1993, 66, 2915-2921. [CrossRef]

40. Chiessi, E.; Paradossi, G.; Venanzi, M.; Pispisa, B. Copper complexes immobilized to chitosan. J. Inorg. Biochem. 1992, 46, 109-118. [CrossRef]

41. Natarajan, A.; Kuznicki, N.; Harbottle, D.; Masliyah, J.; Zeng, H.; Xu, Z. Understanding mechanisms of asphaltene adsorption from organic solvent on mica. Langmuir 2014, 30, 9370-9377. [CrossRef] [PubMed]

42. Kan, Y.; Yang, Q.; Tan, Q.; Wei, Z.; Chen, Y. Diminishing cohesion of chitosan films in acidic solution by multivalent metal cations. Langmuir 2020, 36, 4964-4974. [CrossRef]

43. Zhao, G.; Tan, Q.; Xiang, L.; Zhang, D.; Ni, Z.; Yi, H.; Chen, Y. Imaging the condensation and evaporation of molecularly thin ethanol films with surface forces apparatus. Rev. Sci. Instrum. 2014, 85, 13702. [CrossRef] [PubMed]

44. Israelachvili, J.N. Intermolecular and Surface Forces; Elsevier Science: New York, NY, USA, 2011.

45. Tan, Q.; Zhao, G.; Qiu, Y.; Kan, Y.; Ni, Z.; Chen, Y. Experimental observation of the ion-ion correlation effects on charge inversion and strong adhesion between mica surfaces in aqueous electrolyte solutions. Langmuir 2014, 30, 10845-10854. [CrossRef]

46. Tulpar, A.; Subramanian, V.; Ducker, W. Decay lengths of double-layer forces in solutions of partly associated ions. Langmuir 2001, 17, 8451-8454. [CrossRef] 
47. Futalan, C.M.; Kan, C.-C.; Dalida, M.L.; Hsien, K.-J.; Pascua, C.; Wan, M.-W. Comparative and competitive adsorption of copper, lead, and nickel using chitosan immobilized on bentonite. Carbohydr. Polym. 2011, 83, 528-536. [CrossRef]

48. Kumar, M.; Tripathi, B.P.; Shahi, V.K. Crosslinked chitosan/polyvinyl alcohol blend beads for removal and recovery of Cd(II) from wastewater. J. Hazard. Mater. 2009, 172, 1041-1048. [CrossRef] [PubMed]

49. Mende, M.; Schwarz, D.; Steinbach, C.; Boldt, R.; Schwarz, S. Simultaneous adsorption of heavy metal ions and anions from aqueous solutions on chitosan-Investigated by spectrophotometry and SEM-EDX analysis. Colloids Surf. A Physicochem. Eng. Asp. 2016, 510, 275-282. [CrossRef]

50. Hwang, D.S.; Zeng, H.; Masic, A.; Harrington, M.J.; Israelachvili, J.N.; Waite, J.H. Protein- and metal-dependent interactions of a prominent protein in mussel adhesive plaques. J. Biol. Chem. 2010, 285, 25850-25858. [CrossRef]

51. Guo, Z.; Ni, K.; Wei, D.; Ren, Y. Fe ${ }^{3+}$-induced oxidation and coordination cross-linking in catechol-chitosan hydrogels under acidic pH conditions. RSC Adv. 2015, 5, 37377-37384. [CrossRef]

52. Vorlop, K.-D.; Klein, J. Formation of spherical chitosan biocatalysts by ionotropic gelation. Biotechnol. Lett. 1981, 3, 9-14. [CrossRef]

53. Zeng, H.; Hwang, D.S.; Israelachvili, J.N.; Waite, J.H. Strong reversible $\mathrm{Fe}^{3+}$-mediated bridging between dopa-containing protein films in water. Proc. Natl. Acad. Sci. USA 2010, 107, 12850-12853. [CrossRef]

54. Farina, R.; Laugel, N.; Pincus, P.; Tirrell, M. Brushes of strong polyelectrolytes in mixed mono- and tri-valent ionic media at fixed total ionic strengths. Soft Matter 2013, 9, 10458. [CrossRef]

55. Gourdon, D.; Lin, Q.; Oroudjev, E.; Hansma, H.; Golan, Y.; Arad, S.; Israelachvili, J. Adhesion and stable low friction provided by a subnanometer-thick monolayer of a natural polysaccharide. Langmuir 2008, 24, 1534-1540. [CrossRef] [PubMed]

Publisher's Note: MDPI stays neutral with regard to jurisdictional claims in published maps and institutional affiliations. 